\title{
Looking for "the Big Picture" on a Small Screen: A note on Overview Support in Cooperative Work
}

\author{
Hertzum, Morten
}

\section{Published in:}

Global Thoughts, Local Designs - Revised, Selected Papers from IFIP TC 13 Workshops at INTERACT2017

DOI:

10.1007/978-3-319-92081-8_13

Publication date:

2018

Document version

Peer reviewed version

Citation for published version (APA):

Hertzum, M. (2018). Looking for "the Big Picture" on a Small Screen: A note on Overview Support in Cooperative Work. In Global Thoughts, Local Designs - Revised, Selected Papers from IFIP TC 13 Workshops at INTERACT2017 (Vol. LNCS 10774, pp. 133-139). Springer. Lecture notes in computer science Vol. 10774 https://doi.org/10.1007/978-3-319-92081-8_13 
In T. Clemmensen, V. Rajamanickam, P. Dannenmann, H. Petrie, M. and Winckler (eds.) (2018), Global Thoughts, Local Designs - Revised, Selected Papers from IFIP TC 13 Workshops at INTERACT2017 (Mumbai, IN, Sept. 25-26). LNCS vol. 10774, pp. 133-139. Springer, Cham.

DOI: https://doi.org/10.1007/978-3-319-92081-8_13

\title{
Looking for "the Big Picture" on a Small Screen: A note on Overview Support in Cooperative Work
}

\author{
Morten Hertzum \\ University of Copenhagen, Denmark \\ hertzum@hum.ku.dk
}

\begin{abstract}
Large, shared displays - such as electronic whiteboards - have proven successful in supporting actors in forming and maintaining an overview of tightly coupled cooperative activities. However, in many developing countries the technology of choice is mobile phones, which have neither a large nor a shared screen. It therefore appears relevant to ask: How may mobile devices with small screens support, or fail to support, actors in forming and maintaining an overview of their cooperative activities? This note contrasts the strengths of large, shared displays with those of small, mobile devices and briefly describes the mKrishi app for providing fishers in the Maharashtra state of India with an overview of the locations where there is likely to be many fish.
\end{abstract}

Keywords: overview, awareness, cooperative work, small-screen devices

\section{Introduction}

In tightly coupled collaboration, the actors coordinate their activities by monitoring what the others are doing and by displaying their own activities for others to monitor [1]. The ways in which this monitoring and displaying is accomplished vary across contexts, as evidenced by the considerable research on awareness [e.g., 2] and overview [e.g., 3]. Unless the actors are permanently co-located, awareness and overview must be mediated by technology. These technologies include large, shared displays, which are becoming increasingly common in settings where the actors are locally mobile but co-located part of the time. Hospitals are a prominent example of such work settings. In European and North American hospitals wall-mounted electronic whiteboards are replacing dry-erase whiteboards [4], and the clinicians who use these large, shared electronic displays experience an improved overview of their work [5]. In contrast, the technology of choice in many developing countries is mobile phones with comparatively small screens $[6,7]$. Thus, in systems that target developing countries the need for supporting actors in maintaining an overview of their cooperative work will often have to be accomplished on a small screen.

Before proceeding it should be noted that it obviously is a simplification to associate display size with country. The argument is neither that large, shared displays such as electronic whiteboards are non-existent in developing countries, nor that small 
interfaces are rare in developed countries. Rather, the argument is that the ways in which large, shared displays support actors in maintaining an overview are irrelevant in settings characterized by small interfaces. To develop for these settings we need to understand how small interfaces may support, or fail to support, actors in maintaining an overview of their cooperative work. Clearly, this need is accentuated if the application of large, shared displays is not feasible, economically or otherwise.

\section{Overview and Large, Shared Displays}

Hertzum and Simonsen [8] find that in a collaborative setting with an electronic whiteboard the users adopted a strategy that could be described as: visual overview, oral detail. That is, they glanced at the whiteboard to get "the big picture" and augmented this visually acquired overview with asking their colleagues for clarification and detail. This finding can be seen as a cooperative-work extension of Shneiderman's [9] visual information-seeking mantra (overview first, zoom and filter, then details-on-demand). Specifically, the focus on cooperative work emphasizes that an overview is the users' awareness and understanding of the information relevant in the situation; it is not merely a property or component of a user interface [10]. The overview is a collaborative accomplishment in that the individual actors consult each other for information that elaborates and supplements the information they glean from the whiteboard. Apart from the obvious difference in screen real estate between a $52-$ inch whiteboard and a 4-inch smartphone the large, shared displays have at least three strengths that appear to be absent on small screens:

- Artefactual multiplicity. The whiteboard may hold different pieces of information that are relevant to different groups of users, and it may also interrelate these pieces of information, thereby facilitating the coordination among user groups [11]. The interrelating of the pieces of information is accomplished through their simultaneous presence on the display.

- Social translucence. Because the whiteboard is shared it makes the same information visible to all actors. The actors are, however, not simply made aware of information they are also held accountable: As an actor I know that everybody knows what information I can read on the whiteboard [12]. Thus, actors can rely on each other to glance regularly at the whiteboard and react on its content.

- Information hotspots. In addition to being an information display, the whiteboard also creates a physical place where actors meet [13]. They may visit the area around the whiteboard to interact with the whiteboard or to consult a colleague, who is there to interact with the whiteboard, consult a colleague or make herself available for consultation [14].

While the three strengths are described on the basis of studies of electronic whiteboards, it appears likely that the same strengths exist for wall-size displays, tabletop interfaces, and other large, shared displays. The affordances of small, mobile devices are different. 


\section{Overview and Small, Mobile Devices}

On a mobile device the functionality of the applications is narrowly focused to fit the small screen. This narrow focus reduces the possibilities for artefactual multiplicity. In addition, the personal nature of the device reduces social translucence because it is less apparent to others what information I have available and when I have the opportunity to access it. Finally, the mobility of the device prevents it from functioning as a physical location for actors to meet. While it is tempting to presume that actors who collaborate using small, mobile devices need other means of achieving these three ends, it is also possible that they transmute artefactual multiplicity, social translucence, and information hotspots into alternative ways of gaining and maintaining an overview. Either way, it is important to human work interaction design to understand how the actors gain and maintain the overview they need to conduct their activities cooperatively and competently. Studies of the use of mobile phones in developing countries are beginning to address these issues, but tend to investigate loosely coupled activities. The studied activities include societal as well as local collaborations that exploit the widespread adoption of mobile phones:

- Nearly everybody has a mobile phone, thus making it possible to reach most people with information and include many people in cooperative activities. For example, multiple African initiatives use mobile phones as tools to disseminate and collect health information via text messages, to improve the transparency and accountability of elections by sending local observations about polls to central monitoring groups, and to promote reforestation by transferring payments to rural farmers for planting trees [7].

- The actors carry their mobile phones everywhere, attend to them repeatedly, and may, thereby, interact with each other when needed rather than when they happen to be in the same place at the same time. For example, geographically distributed herders of livestock in rural Kenyan communities use mobile phones to share information about the changing location of water resources for the livestock and of rangers likely to disrupt herding practices [15].

- Mobile phones can broadcast information about the whereabouts and activities of actors, thereby providing information for others to monitor. However, this possibility may primarily have been exploited in developed countries. For example, studies of collaborative web search have found that such activity information supports remotely located actors in aligning their search activities and progressing on a shared task [16].

The ways in which mobile devices may support actors in forming and maintaining an overview of their cooperative activities appear an important research area. Similarly, it is important to research the ways in which cooperative work arrangements may transmute what overview is about or what role technology plays in supporting it. This research should, in particular, attend to the conditions in developing countries, in which mobile phones are widespread whereas large-display technologies are not. 


\section{Example: Use of mKrishi App by Alibaug Fishers}

In coastal Indian villages fishing provides jobs and income for nearly a million fishers and even more people in the processing and marketing of the landed fish. To support the fishers in the Maharashtra state an app for mobile phones has been developed in a decade-long collaboration between Tata Consultancy Services (TCS), Innovation Lab Mumbai, Central Marine Fisheries Research Institute (CMFRI), Indian National Center for Ocean Information Services (INCOIS), Indian Council of Agricultural Research (ICAR), and local fishery societies. Maharashtra has a coastline from Mumbai in the north and 720 kilometers southward. One of the fishery villages along the coastline is Alibaug (Fig. 1), which we visited in September 2017.
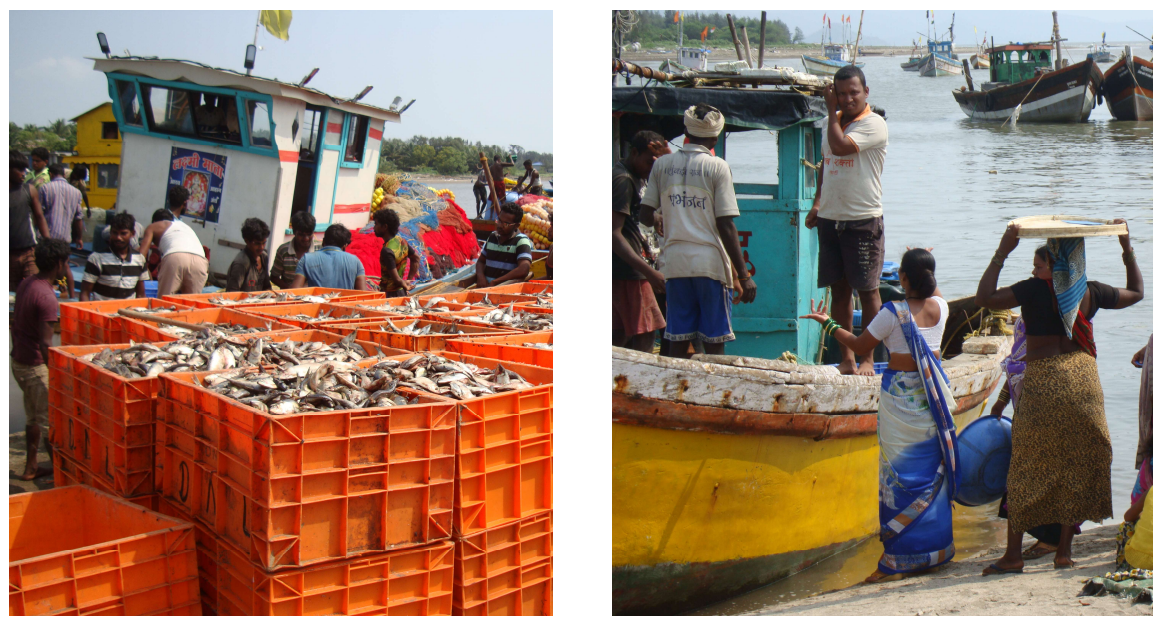

Fig. 1. Fisheries landing center in Alibaug village. Photos by the author.

The app, mKrishi, is freely available to the fishers. Its main feature is a map indicating the locations at which the concentration of fish is predicted to be high at the moment. The predictions are derived from satellite data about the thermal fronts in the water and the water color. For example, the water color gives an indication of the amount of plankton, which is a crucial source of food for the fish. Thus, a large amount of plankton is likely to coincide with a high concentration of fish. A second important feature of the app is weather forecasts, specifically forecasts of the speed and direction of the wind. See Fig. 2 for screenshots of these two features of the mKrishi app. In addition, the app provides information about good fishing practices and a few other issues. With respect to gaining an overview the app has affected the fishers' ways of working in multiple ways:

- After the introduction of the app the fishers use less diesel. It has been possible to document this reduction at the community level because the distribution of diesel is the responsibility of the local fishery societies and they keep careful records. The reduced diesel consumption indicates that (a) the fishers engage in less searching to find the fish and (b) select routes with more tailwind when they are 
returning with their catch to one of the landing centers along the coastline. The former suggests a better overview of the location of the fish, the latter a better overview of the weather conditions.
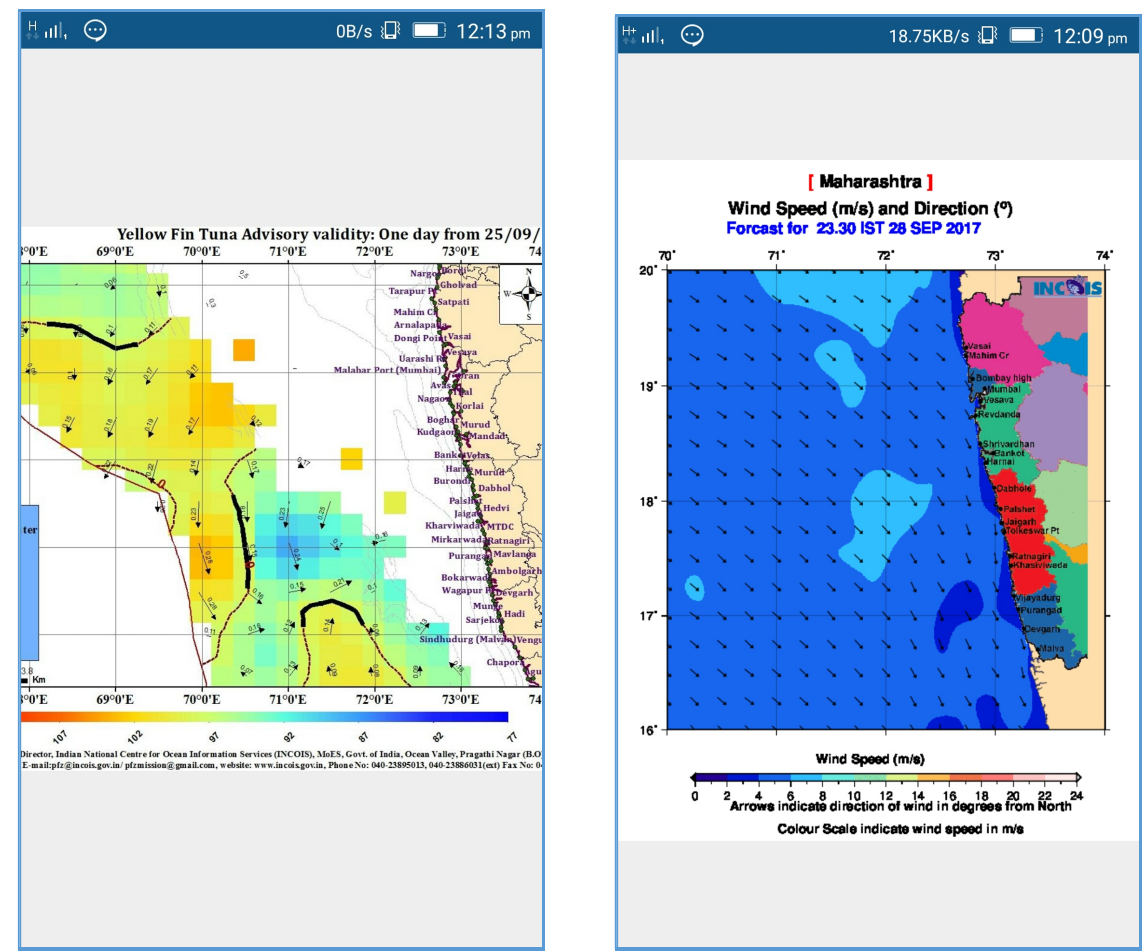

Fig. 2. The mKrishi app showing the predicted location of fish (left) and the forecast for wind speed and direction (right). Screenshots courtesy of TCS, Innovation Lab Mumbai, ICAR, CMFRI Mumbai, and INCOIS.

- Previously, fishers would often try to keep it a secret if they had a hunch about where to go to get a good catch. Now, up-to-date information about where fish can most likely be found is available to all the fishers. The chairperson of the Alibaug fishery society considered this equal access to information a benefit; individual fishers may agree or disagree. With the app the fishers have an increased need to coordinate, or negotiate, who goes where to avoid going to the same place. The app provides no support for this coordination and creates no physical meeting place for it.

- In its current version the app appears to bypass the cooperative aspects of the fishers' work. The fishers have proposed to extend the app with information about the price at which different fish can currently be sold at nearby landing centers. Another possible extension would be to track the location of the fisher boats. Knowing their location could help in coordinating who goes where and in coming to rescue during emergencies, which are all too frequent. Instead of 
artefactual multiplicity, the app pursues a fairly singular purpose. Activities related to, but different from, this purpose are handled through other arrangements, such as the fishery society for coordination/negotiation and the control center for emergency response.

The mKrishi app does not have the strengths of a large, shared display but it has enabled the fishers to gain a better overview of the location of fish and the possibilities for tailwind back to the coast. The app is but one component in a large sociotechnical network and has been designed to improve, not obliterate, this network. While many things are best handled outside the app, it appears worthwhile to consider including some support for the cooperative aspects of the fisher's work.

\section{Conclusion}

Forming and maintaining an overview is pertinent to the competent performance of cooperative work. While technical support for forming and maintaining an overview has received considerable research attention in developed countries with ample access to large, shared displays, less is known about how small, mobile devices may support - or fail to support - actors in developing countries in overviewing their cooperative activities. The mKrishi app illustrates that at least some aspects of an overview can be provided on a small, mobile device but also that it is important to consider how overview support is distributed between the app and the other systems and arrangements that form the sociotechnical network in which the app is embedded.

\section{References}

1. Schmidt, K.: The problem with 'awareness'. Computer Supported Cooperative Work 11(3\&4), 285-298 (2002).

2. Gross, T.: Supporting effortless coordination: 25 years of awareness research. Computer Supported Cooperative Work 22(4), 425-474 (2013).

3. Bossen, C., Jensen, L.G.: How physicians 'achieve overview': A case-based study in a hospital ward. In: Proceedings of the CSCW2014 Conference on Computer Supported Cooperative Work \& Social Computing, pp. 257-268. ACM Press, New York (2014).

4. Rasmussen, R.: Electronic whiteboards in emergency medicine: A systematic review. In: Luo, G., Liu, J., Yang, C.C. (eds.) Proceedings of the IHI2012 International Health Informatics Symposium, pp. 483-492. ACM Press, New York (2012).

5. Hertzum, M.: Electronic emergency-department whiteboards: A study of clinicians' expectations and experiences. International Journal of Medical Informatics 80(9), 618-630 (2011).

6. Nottebohm, O., Manyika, J., Bughin, J., Chui, M., Syed, A.-R.: Online and upcoming: The internet's impact on aspiring countries. McKinsey \& Company (2012). 
7. Etzo, S., Collender, G.: The mobile phone 'revolution' in Africa: Rhetoric or reality? African Affairs 109(437), 659-668 (2010).

8. Hertzum, M., Simonsen, J.: Visual overview, oral detail: The use of an emergency-department whiteboard. International Journal of Human-Computer Studies 82, 21-30 (2015).

9. Shneiderman, B.: The eyes have it: A task by data type taxonomy for information visualizations. In: Proceedings of the 1996 IEEE Conference on Visual Languages, pp. 336-343. IEEE Press, Los Alamitos, CA (1996).

10. Hornbæk, K., Hertzum, M.: The notion of overview in information visualization. International Journal of Human-Computer Studies 69(7\&8), 509-525 (2011).

11. Bjørn, P., Hertzum, M.: Artefactual multiplicity: A study of emergencydepartment whiteboards. Computer Supported Cooperative Work 20(1\&2), 93121 (2011).

12. Erickson, T., Kellogg, W.A.: Social translucence: An approach to designing systems that support social processes. ACM Transactions on Computer-Human Interaction 7(1), 59-83 (2000).

13. Scupelli, P., Xiao, Y., Fussell, S.R., Kiesler, S., Gross, M.D.: Supporting coordination in surgical suites: Physical aspects of common information spaces. In: Proceedings of the CHI 2010 Conference on Human Factors in Computing Systems, pp. 1777-1786. ACM Press, New York (2010).

14. Hertzum, M., Reddy, M.: Procedures and collaborative information seeking: A study of emergency departments. In: Hansen, P., Shah, C., Klas, C.-P. (eds.) Collaborative Information Seeking: Best Practices, New Domains and New Thoughts, pp. 55-71. Springer, Berlin (2015).

15. Butt, B.: Herding by mobile phone: Technology, social networks and the "transformation" of pastoral herding in East Africa. Human Ecology 43(1), 1-14 (2015).

16. Morris, M.R., Horvitz, E.: SearchTogether: An interface for collaborative web search. In: Proceedings of the UIST2007 Symposium on User Interface Software and Technology, pp. 3-12. ACM Press, New York (2007). 